\title{
Typhoid is over-reported in Embu and Nairobi, Kenya
}

\author{
Samuel Kariuki ${ }^{1 *}$ Joyce Mwituria $^{1}$, Agnes Munyalo ${ }^{1}$, Gunturu Revathi ${ }^{2}$ and \\ Joyce Onsongo ${ }^{3}$
}

1. Kenya Medical Research Institute, Centre for Microbiology Research P.O. Box 43640, Nairobi. 2; Department of Medical Microbiology, Kenyatta National Hospital, Nairobi, 3; Division of Disease Outbreak Management Unit, Division of Communicable Diseases, Ministry of Health PO Box 2078, Nairobi.

* Address for Correspondence: Tel:254-202-718247; Fax:254-202-711673;

E-mail: skariuki@wtnairobi.mimcom.net

\section{SUMMARY}

The paper looks at the usefulness of the Widal agglutination test in the context of variable normal antibody titres in two different populations in Kenya, and in comparison to the blood culture method of diagnosis. It presents a prospective case-control study. We examined 846 blood cultures and an equal number of serum samples, and 782 stools from adults who presented at two study sites; Kenyatta National Hospital and one hospital and 3 clinics in Embu District, with symptoms similar to typhoid. Examined also were 360 serum samples and stools from adults who were apparently healthy (controls) who sought routine medical examination at the study sites. From blood cultures, isolation rates for typhoid for Embu $(3 \%)$ and Nairobi $(2.2 \%)$ were not significantly different $(p>0.01)$. In addition the control population from the two study sites did not show any significant background $O$ antibody titre levels characteristic of typhoid endemic areas. All the 7 commonly available Widal test kits including Murex, Europath, Biotech, Humatex, Biosystems, Microsystems and Typhex, that were evaluated for efficacy were equally specific in diagnosis of typhoid by Widal agglutination methods. However, there were minor differences in the sensitivities of the kits. The Widal test method gave a lower sensitivity $(81.3 \%)$ than specificity $(93 \%)$ when compared to the culture of blood for diagnosis of typhoid. Going by the reports of typhoid outbreaks in Embu and Nairobi (ca. 20-25\% reported prevalence) we conclude that there has been over-reporting probably due to poor methodologies of performing the Widal test. We recommend adequate clinical examination in suspected cases of typhoid in addition to proper Widal in order to improve typhoid diagnosis. Newer improved methods that are more specific and sensitive than the Widal test need to be evaluated in improving laboratory diagnosis of typhoid.

\section{Introduction}

Salmonella enterica serovar Typhi (S. typhi) causes some 10 million cases of typhoid fever resulting in over 600,000 deaths each year, particularly in resource poor countries $[1,2$, 3]. The disease is acquired by eating food or drinking water contaminated with faeces or urine from infected persons. Untreated typhoid fever is life threatening, with high mortality occurring in immunosuppressed individuals, young children and the elderly. Up to $70 \%$ of adult patients show a rise in antibody titre in the first week of infection, which forms the 
basis for the Widal test in diagnosis of typhoid fever. The disease persists for up to six weeks during which complications such as haemorrhage, perforation of the ileum and sepsis involving meningitis may occur [4].

Lately there have been reports from several parts of Kenya indicating that typhoid outbreaks are increasingly becoming a major public health problem. However, we do not know the extent to which these reports of typhoid outbreaks are true; are we observing incidences of over diagnosis or do we genuinely have an upsurge in typhoid outbreaks? The problem of over diagnosis of typhoid in Kenya has been raised previously $[5,6,7]$.

To-date however, no definite steps have been taken to address the problem and to formulate useful diagnostic criteria. Culture of blood from suspected cases is thought to be the gold standard in diagnosis of typhoid fever. The ELISA test has also been used to check for significant rise in $\mathrm{O}$ antibody titres but the test is too expensive and also time consuming compared to the Widal test, and therefore may not be affordable for most laboratories. Also blood culture facilities are not widely available in District Hospital laboratories and most private laboratories in the rural areas, and even for culture it takes about three days from collection of specimen to availability of results [7]. Unfortunately antibody titres in normal persons vary between endemic and non-endemic typhoid areas yet many laboratories report only absolute titre levels for patients. For example, in endemic areas in tropical countries [ 8] active typhoid is suggested if the antibody titres are significantly raised (ie titres greater than 1 in 180 or 1 in 200 depending on the titres found in the local healthy people). Lack of basic data on "normal" antibody titres in the general population particularly in typhoid endemic areas hampers proper interpretation of titration results even when sensitivity and specificity of the Widal test kit are well established. Studies evaluating the usefulness of the Widal agglutination test for diagnosis of typhoid in Vietnam [9] found that it was possible to correctly diagnose $74 \%$ of the blood culture positive cases. However, for this to happen both laboratory and clinical staff that deal with suspected cases of typhoid require data and information on diagnostic criteria that would improve sensitivity and specificity of their tests.

In the current study we set out to evaluate methods being currently used for the diagnosis of typhoid and determine if these are adequate to make a definite diagnosis of typhoid. We aimed to identify key weaknesses in the procedures used in making clinical and laboratory diagnosis of typhoid with the aim of improving on these. The principal objectives of the study were to evaluate the sensitivity and specificity of the Widal test as the most commonly used laboratory method compared to culture of blood, for the diagnosis of typhoid in selected "endemic areas" of Kenya and to develop guidelines for improved diagnosis of typhoid.

\section{Research Design and Methods}

\section{Study sites and patients:}

The study sites were Embu Provincial Hospital, TENRI clinic and Runyenjes District Hospital - all in Embu, and Kenyatta National Hospital. This was a prospective case control study matched for age and time of recruitment. $A$ case was defined as an adult ( $>18$ years) patient with febrile illness consenting to the study and whose blood culture was positive for $S$. typhi. A control was defined as a healthy adult (afebrile) from the study areas matched for age and time of recruitment. Informed consent for participation in the study was sought and explained in the language understood by the participant.

\section{Sampling}

Patients were recruited consecutively from the outpatient departments. Each suspected case of typhoid was reviewed by a qualified clinical officer in-charge. Vital parameters were taken and entered into a patient data sheet. Other clinical conditions that may cause false positive $O$ antibody reactions such as rheumatoid arthritis, chronic liver disease, nephrotic syndrome and ulcerative colitis were evaluated at clinical examination. A venepuncture was done aseptically on each patient during the acute febrile phase and 15 $\mathrm{mL}$ blood was drawn once to be used for all tests. Five millilitres of blood was inoculated each into two blood culture bottles containing $50 \mathrm{~mL}$ brain heart infusion broth and the remaining $5 \mathrm{~mL}$ was drawn into sterile 
RESEARCH ARTICLES

heparinized vacutainers for separation of serum for use in Widal tests. Separated serum was stored at $-70^{\circ} \mathrm{C}$ until analysed. In addition a stool sample was taken from each patient in order to assess carrier status for typhoid fever.

\section{Laboratory procedures. \\ Blood cultures}

Blood cultures were incubated in $5 \% \mathrm{CO}_{2}$ at $37^{\circ} \mathrm{C}$ and subsequently subcultured after $24 \mathrm{~h}$ onto blood, chocolate and MacConkey agar plates (Oxoid Ltd., Basingstoke, UK). An optochin disk (Oxoid) was placed onto the blood agar plate to detect any Streptococcus pneumoniae. The blood cultures were subsequently observed for a further 7 days for signs of bacterial growth including gas production and turbidity. Bacteria of clinical significance, including those that may mimic typhoid (syphilis, non-typhi Salmonella spp) in elevating specific $O$ antibody titres were identified using the Analytical Profile Index (API System, Motalieu Vercieu, France).

\section{Stool cultures}

These were done by direct plating onto selective media (XLD and brilliant green agar) and by overnight enrichment in selective broth (selenite F) followed by plating onto XLD and brilliant green agar (Oxoid). Non-lactose fermenting bacteria were identified biochemically using the API test kit. All significant enteric bacteria such as Salmonella spp, E. coli and Shigella spp were identified from stools in order to control for false positive reactions in the Widal test.

\section{Widal agglutination test}

Sera from cases and controls were tested for agglutination using seven commonly available Widal test kits: Murex (Murex Biotech Ltd., Dartford, UK), Biotech (Biotech Laboratories Ltd, Suffolk, UK), Europath (Euromediequip Ltd., Middlesex, UK), Biosystems (Biosystems, Barcelona, Spain), Humanex (Human Diagnostica GmbH, Wiesbaden, Germany), Micropath (Omega Diagnostics Ltd., Alloa, Scotland) and Typhex (Life Technologies, Nairobi, Kenya), according to manufacturer's instructions.

\section{Determination of titre levels}

Sera from cases and controls were evaluated for antibody titre levels using the seven Widal agglutination test kits,
manufacturer's instructions.

according to

\section{Results}

\section{Sample collection}

During the study period from Jan 2002 to March, 2003 we examined 340 blood and serum samples, and 382 stools from adults who presented to 3 study hospitals and clinics (Embu Provincial Hospital, TENRI clinic and Runyenjes District Hospital - all in Embu District) with typhoid-like symptoms headache, nausea, fever and occasional chills. During the same period we examined 360 serum samples and a corresponding number of stools from adults who were apparently healthy and only reported to the hospitals for Medical Examination for issuance of Food Handlers' Health Certificates. We also obtained $54 S$. typhi from Kenyatta National Hospital that had been isolated from a total of 2450 blood cultures of adults. Of these patients serum samples were available only from a total of 506 patients including the culture positive cases.

\section{Comparison of blood cultures and Widal agglutination tests}

Salmonella typhi was isolated from 10 out of 340 blood cultures examined (an isolation rate of $3 \%$ ); all came from patients seen at the Embu Provincial Hospital. Other isolations of clinical significance were coagulase positive Staphylococcus species from 4 blood cultures. Only three patients had both blood and stool culture positive for $S$. typhi. From Kenyatta National Hospital, a total of $54 S$ typhi isolates were obtained (an isolation rate of $2.2 \%$ ). Serum samples from the 2 study sites were enough to perform agglutination and titration using only 3 kits the Murex, Biosystems and Typhex were selected based on preliminary sensitivity results. From the 10 positive blood cultures from the Embu study site 3 were negative for $\mathrm{O}+\mathrm{H}$ antibodies. A total of 4 were positive for $\mathrm{O}$ and $\mathrm{H}$ antibodies with $O$ and $H$ titres of $O 1: 160$ and $H 1: 320$, respectively. One sample was positive only for $\mathrm{H}$ antibody only and therefore was not titrated.

Thirty-five other serum samples from suspected cases of typhoid from the Embu site were positive for $\mathrm{H}$ antibody only and were not titrated. From the Nairobi study site a total of 48 out of 54 serum samples from blood 
culture positive cases gave variable titre levels for $O$ antibody, and 6 others did not show any agglutination.

\section{Widal test for negative blood cultures and} stools

Serum samples from 11 patients from Embu whose blood was sterile showed a reaction with Widal test but only 8 showed titres between $1: 20$ to $1: 320$ for $O$ antibody and $1: 20$ to $1: 640$ for the $\mathrm{H}$ antibody. It is probable, from the history of the patients, that they had had antibiotic treatment prior to coming to hospital, hence the sterile blood cultures. From the Nairobi study site a total of 44 serum samples were also false positive. Stool samples from controls were all negative for pathogenic bacteria.

\section{Widal agglutination test for control sera}

From the Embu study site only 5/240 serum samples agglutinated with the test kits.
However, upon titration none of the sera gave a significant rise in titre levels. From the Nairobi study site a total of 50/120 showed raised titres to $\mathrm{O}$ antibody but titres for the $\mathrm{H}$ antibody were only significant in 75 of the serum samples. Using the $O$ antibody reaction as criteria for detection of typhoid, this means a total of 50 samples were false positive.

\section{Comparison of efficacy of the commonly available Widal test kits}

A total of 54 serum samples from confirmed cases of typhoid from Kenyatta National Hospital were tested (Table 1). Out of these 40 had $\mathrm{O}$ antibody titre levels ranging from $1: 20$ to $1: 1280$, 6 did not show any agglutination while 8 others had titre levels below $1: 20$. Only 5 of serum samples showed any significant rise in $\mathrm{H}$-antibody titre levels. These 40 serum samples were used to assess the efficacy of the seven commonly available Widal test kits.

Table 1. Titre levels of agglutinating sera using Murex, Bisoystems and Typhex kits

\begin{tabular}{|lll|ll|}
\hline O antibody titre level & No. of samples & H antibody titre & No. of samples \\
\hline $1: 20$ & - & 1 & $1: 20$ & - NIL \\
$1: 40$ & - & 6 & $1: 40$ & -1 \\
$1: 80$ & - & 6 & $1: 80$ & - NIL \\
$1: 160$ & - & 16 & $1: 160$ & -1 \\
$1: 320$ & - & 8 & $1: 320$ & - NIL \\
\hline $1: 640$ & - & 2 & $1: 640$ & -2 \\
$1: 1280$ & - & 1 & $1: 1280$ & -1 \\
TOTAL & & 40 & TOTAL & 5 \\
\hline
\end{tabular}

From the tests of comparison we observed that only the $O$ antibody (always most reliable in reaction to typhoid infection) showed titre levels consistent with $S$. typhi infection. Titre levels of $1: 80$ to $1: 320$ (Mode 1:160) were most predictive of infection with $S$. typhi. Most of the seven kits used were available in various clinical laboratories at the two study areas, although the Typhex, Humatex and Europath were more commonly used. Forty sets of sera from confirmed typhoid cases and their controls were used to assess sensitivity and specificity of each test kit (Tables 2 and 3). Where samples were positive, Typhex, Micropath and Biosystems sometimes took longer than the specified time to react. Where samples were positive and using the slide agglutination method all the 7 kits agglutinated with sera within the specified 
time for reaction. However, on using the tube titration method, the Typhex, Micropath and Biosystems kits took $10-30 \mathrm{sec}$ longer than the stipulated reaction time. As would be expected
O antibody had a slower reaction with all the kits, $H$ antibody reaction always appeared first.

Table 2: Comparative Sensitivities of the Widal Test kits

\begin{tabular}{|l|l|l|}
\hline KIT & STIPULATED ROCKING-TIME & $\begin{array}{l}\text { TIME-TAKEN USING } \\
\text { CULTURE-POSITIVE SERA }\end{array}$ \\
\hline Murex & $1 \mathrm{Min}$ & $30-60 \mathrm{Sec}$ \\
\hline Biotech & $1 \mathrm{Min}$ & $40-60 \mathrm{Sec}$ \\
\hline Europath & $1 \mathrm{Min}$ & $30-60 \mathrm{Sec}$ \\
\hline Biosystems & $2 \mathrm{Min}$ & $1-2 \mathrm{Min}$ \\
\hline Typhex & $1-2 \mathrm{Min}$ & $2 \mathrm{Min}$ and above \\
\hline Humatex & $1 \mathrm{Min}$ & $40-60 \mathrm{sec}$ \\
\hline Micropath & $1 \mathrm{Min}$ & $1-2 \mathrm{~min}$ \\
\hline
\end{tabular}

Table 3 : Evaluation of the Widal test method for sensitivity and specificity

$$
\text { Blood culture test (Typhoid disease] }
$$

\begin{tabular}{rlll} 
& Yes & No & Total \\
\cline { 2 - 4 } Widal test +ve & 52 & 55 & 107 \\
\hline Widal test - ve & 12 & 727 & 739 \\
\hline Total & 64 & 782 & 846
\end{tabular}

Specificity: From Table 3 specificity $=727 / 782 \times 100=93 \%$. This means a false positive rate of $7 \%$ for the Widal test results using samples from our two study sites.

Sensitivity:_From Table 3 sensitivity $=52 / 64 \times 100=81.3 \%$. This means a false positive rate of $18.7 \%$ if the Widal test was used solely as criteria for diagnosis of typhoid.

\section{Discussion}

Due to a combination of factors including poor sanitation and health care infrastructure, typhoid fever remains a major public health problem in most resource poor countries $[2,10]$. In developed countries, the incidence of cases and death has been greatly decreased by a combination of improved sanitation and hygiene, vaccines and effective antimicrobial chemotherapy. In Kenya there have been reports of sporadic outbreaks of typhoid but these cases have not always been confirmed leading to paucity in quality data on the prevalence of typhoid in many parts reporting outbreaks. Some of the areas that have reported outbreaks previously were Embu, Nairobi, Nakuru and Kiambu Districts.
For many decades now isolation of $S$. typhi from a blood or bone marrow culture from patients has been regarded as a definitive diagnosis for typhoid [11]. However many laboratories in developing countries lack adequate infrastructure to perform culture and many depend on the cheaper serological tests for diagnosis of typhoid. In the current study using blood culture as a gold standard criterion for the diagnosis of typhoid we observed that throughout the 16 month study the incidence of typhoid in Embu District and Nairobi was not significantly different (3\% and $2.2 \%$, respectively) (p-value > $0.01)$. These incidence rates are much lower than previously reported from these study sites; rates of upto $25 \%$ during early 2001 were reported (unpublished data). The prevalence rates are also much lower than 
has been reported from regions where typhoid is endemic such as Vietnam and other SE Asian countries where prevalence rates were up to $30 \%$ [9]. For all the three kits we used with all 746 serum samples the Widal test method gave a lower sensitivity (81.3\%) than specificity (93\%) when compared to the culture of blood for diagnosis of typhoid. This means that if used alone the Widal agglutination test method would have missed out $7 \%$ of typhoid cases from the two study sites, while at the same time categorise another $18.7 \%$ as typhoid cases when they were not. If used together with a combination of clinical examination and history taking the positive predictive value for the test would undoubtedly be raised.

Other studies in endemic areas of Vietnam [9] reported false negative rates of $17 \%$, which is significantly higher than for our study $(\mathrm{p}<0.01)$. For both study sites only the $\mathrm{O}$ antibody titre levels were diagnostic (70\% for cases from Embu versus $74 \%$ for cases from Nairobi study site) as few samples showed any significant rise in $\mathrm{H}$ antibody titres.

In other studies carried out in endemic regions of India [12], the overall sensitivity of the Widal test was $64.49 \%$ for the O antibody and $78.26 \%$ for the $\mathrm{H}$ antibody. Hence in their study the $\mathrm{H}$ antibody was regarded as more diagnostic, and this contrasts with our findings where $O$ antibody titre levels were observed to be more predictive of typhoid. Reports from other studies also indicate that $\mathrm{O}$ antibody titres were more useful than $\mathrm{H}$ antibody titres in diagnosis of typhoid using the Widal test method $[9,13]$.

A total 55 out of 846 serum samples tested gave significant $\mathrm{O}$ antibody titres and these were from patients from whom no bacteria were isolated from blood. This may be explained by the fact that some of the patients may have taken antibiotics prior to hospitalisation hence making blood cultures sterile. Compared to serological methods this is one of the weaknesses of overreliance on blood culture as the sole diagnostic criteria for typhoid. We found out that if $\mathrm{O}$ antibody titres were high irrespective of culture results a presumptive diagnosis of typhoid would still be made, and this would be confirmed by considering clinical manifestations of the patient. In addition a clinician needs to consider other differential diagnosis that would manifest serologically with raised $\mathrm{O}$ antibody titres, including schistosomiasis, malaria, rheumatoid arthritis, nephrotic syndrome and ulcerative colitis, non-typhoidal salmonellae and chronic liver disease [13, 14, 15].

Using serum samples from the control population from the Embu study site we observed that only $5(2 \%)$ samples showed any agglutination but none had any significant rise in titre levels of either $\mathrm{O}$ or $\mathrm{H}$ antibodies. A total of $50(41.6 \%)$ serum samples from controls from the Nairobi study site showed high $\mathrm{H}$ antibody titres while $\mathrm{O}$ antibody titres (which are diagnostic for typhoid) remained low and insignificant. This we attributed to recent inoculation with typhoid vaccine for workers from the hotel industry. Background titre levels of $O$ antibody that would be indicative of exposure of the population to previous episodes of typhoid were therefore low and our study sites may not be considered endemic for typhoid. In most endemic areas such as in India, Vietnam and SE Asia high background $O$ and $\mathrm{H}$ antibody titre levels in the general population present a major challenge in the interpretation of the Widal test results $[2,9]$

The comparison of efficacy of seven commonly available Widal test kits showed that the Murex kit was most sensitive, followed by Europath, Biotech, Humatex, Biosystems, Micropath, Microsystems and last of all Typhex, in that order. Apart from the Typhex kit that showed agglutination in more than the stipulated time for 8 out of 40 serum samples tested, all other 6 kits tested showed agglutination within time period stipulated in their manufacturer's instructions for use. However, all the kits were similar in their specificity to the Widal test for sera from the two study sites. One major weakness observed in laboratories performing the Widal tests was prolonged rocking of serum-antiserum mixture on slides often leading to a false positive reaction.

The current study had a number of limitations. Due to the low prevalence of typhoid at the Embu study site we were unable to obtain numbers proportionate to 
those from the Nairobi study site, hence the analysis is skewed towards the larger sample size of positive cases from the Kenyatta National Hospital. For the patients from Kenyatta National Hospital we were able to obtain only 506 serum samples from a total of 2450 patients suspected to have typhoid (regardless of culture results). In addition although we attempted to obtain previous history of antibiotic treatment prior to hospitalisation of patients this information was not always forthcoming. This may explain why some of the antibody $\mathrm{O}$ positive sera from patients did not yield any bacteria from blood cultures. Some of the patients came to hospital after several days of illness at home and therefore we did not always obtain specimens during the peak infective stage during mid-first stage bacteremia. It is possible that we may have missed on some of the peak $O$ antibody reactivity in serum. Due to the fact that patients were discharged to convalesce at home we were also unable to obtain convalescent serum that would have enabled us to establish changes in titre levels for $\mathrm{O}$ and $\mathrm{H}$ antibodies that would be characteristic of typhoid fever.

In conclusion, our study observed that the incidence rates for typhoid in Embu and Nairobi were low. Although culture of $S$. typhi from blood is considered as a gold standard in the diagnosis of typhoid the Widal test would still be useful as a rapid diagnostic method so long as laboratory workers followed manufacturer's instructions for use on sera from patients whose clinical examination raised suspicion of typhoid. As some other disease conditions such as malaria, non-typhoidal salmonellae rheumatoid arthritis, chronic liver disease, nephrotic syndrome and ulcerative colitis may show similar symptoms and produce high " $O$ " antibody titres these should also be evaluated as differential diagnosis in order to reduce cases of false positive Widal test results. We also recommend that other rapid identification tests such as the IgM dipstick, which detects IgM antibodies against whole cell serotype $S$. typhi, be evaluated for use in Kenya as the test has been found to be more sensitive than the Widal test in several studies in SE Asia [16]. Caution should be taken in interpretation of titre levels in Kenya as the universal 0:80 cut-off criteria may not apply in areas that are non-endemic for typhoid disease.

\section{Acknowledgments}

We thank the Director, KEMRI for permission to publish these data. We acknowledge support from technical staff at the Embu Provincial Hospital, especially Mr Harrison Munyi, staff from the TENRI children's clinic, Runyenjes sub-district Hospital and the ARIMI private Laboratory in Embu. In addition we thank technical staff at the Department of Medical Microbiology, Kenyatta National Hospital for support in the study. This study was supported by the Rockefeller Foundation ACA Grant No. 2001 AR070

\section{References}

1. Mirza $\mathrm{SH}$; Beeching $\mathrm{NJ}$; and Hart $\mathrm{CA}$. Multi-drug resistant typhoid: a global problem. Journal of Medical Microbiology. 1996; 44: 317-319.

2. Pang T; Levine MM; Ivanoff B; Wain J; and Finlay BB. Typhoid fever: important issues still remain. Trends in Microbiology, 1998; 6: 131-133.

3. Kariuki S; Gilks C; Revathi G and Hart CA. Genotypic analysis of multidrug-resistant Salmonella enterica Serovar Typhi, Kenya. Emerging Infectious Diseases. 2000; 6: 649651.

4. Sirinavin S; Jayanetra P; and Thakkinstian A. Clinical and prognostic cetegorization of extraintestinal nontyphoidal Salmonella infections in infants and children. Clinical Infectious Diseases. 1999; 29: 1151-1156.

5. Petit PL and Wamola IA. Typhoid fever: a review of its impact and diagnostic problems. East African Medical Journal. 1994; 71:183-188.

6. Mirza NB. Diagnosis and over diagnosis of typhoid fever, East Africa Medical Journal. 1995; 72: 753-754.

7. Rees PH. Typhoid fever and the Widal test. East African Medical Journal. 1999;76: 359-360.

8. Sommerville PC. The Widal test in the diagnosis of typhoid fever in the Transvaal. South African Medical Journal. 1981;59: 851-854.

9. Parry CM; Hoa NTT; Diep TS; Wain J; Chinh NT; Vinh H; Hien TT; White NJ and 
Farrar JJ. Value of a single-tube Widal test in diagnosis of Typhoid Fever in Vietnam. Journal of Clinical Microbiology. 1999;37: 2882-2886.

10. Ling JM; Lo NWS; Ho YM; Kam KM; Nguyen TTH; Li TP and Cheng AF. Molecular Methods for the Epidemiological Typing of Salmonella enterica Serotype Typhi from Hong Kong and Vietnam. Journal of Clinical Microbiology. 2000;38: 292-300.

11. Hoffman SL; Punjabi NH; Rockhill RC; Sutomo A; Rivai AR and Pulungsih SP. Duodenal string-capsule culture compared with bone-marrow, blood and rectal-swab cultures for diagnosing typhoid and paratyphoid fever. Journal of Infectious Diseases. 1984;149: 157-161.

12. Shukla S, Patel B and Chintis DS. 100 years of Widal test and its reappraisal in an endemic area. Indian Journal of Medical Research. 1997 105: 53-57.

13. Pang $T$ and Puthucheary SD. Significance and value of the Widal test in diagnosis of typhoid fever in an endemic area. Journal of Clinical Pathology. 1983; 36:471-475.

14. Senewiratne $B$ and Senewiratne $K$. Reassessment of the Widal test in the diagnosis of typhoid. Gastroenterology. 1977; 73:233-236.

15. Sharma JR; Parma IB; Sharma SJ and Kesavan A. False positive Widal reaction in malaria. Indian Journal of Pediatrics. 1993; 30: 1343-1347.

16. House D; Wain J; Ho VA; Diep TS; Nguyen TC; Bay PV; Vinh H; Duc M; Parry CM; Dougan G; White NJ; Hien TT and Farrar JJ. Serology of Typhoid Fever in an area of endemicity and its relevance to diagnosis Journal of Clinical Microbiology. 2001; 39: 1002-1007. 